\title{
Congenital bilateral absence of diaphragm
}

\author{
NURIA TORAN AND JOHN L EMERY \\ From the Department of Pathology, Ciudad Sanitaria de La Seguridad Social, Barcelona, Spain \\ and Department of Pathology, Children's Hospital, Sheffield
}

Diaphragmatic hernia occurs in one in 2000 births $^{1}$ and is responsible for $8 \%$ of congenital malformations causing death during the first few days after birth. ${ }^{2}$ The most common hernia occurs through the foramen of Bochdalek and is five times more common on the left side than on the right. ${ }^{3}$ Complete absence of the diaphragm is very rare and, in a series of 117 cases of diaphragmatic hernia in infants and children, Baffes did not encounter a single case. ${ }^{4}$

We report here a case of total agenesis of the peripheral diaphragm with underdevelopment of the lungs.

\section{Case report}

A female infant was born to a 21-year-old gravida 1, para 1 , mother of blood group $O \mathrm{Rh} D$ positive. Foetal movements were felt at 22 weeks. The pregnancy was uncomplicated until the thirtieth week, when spon-

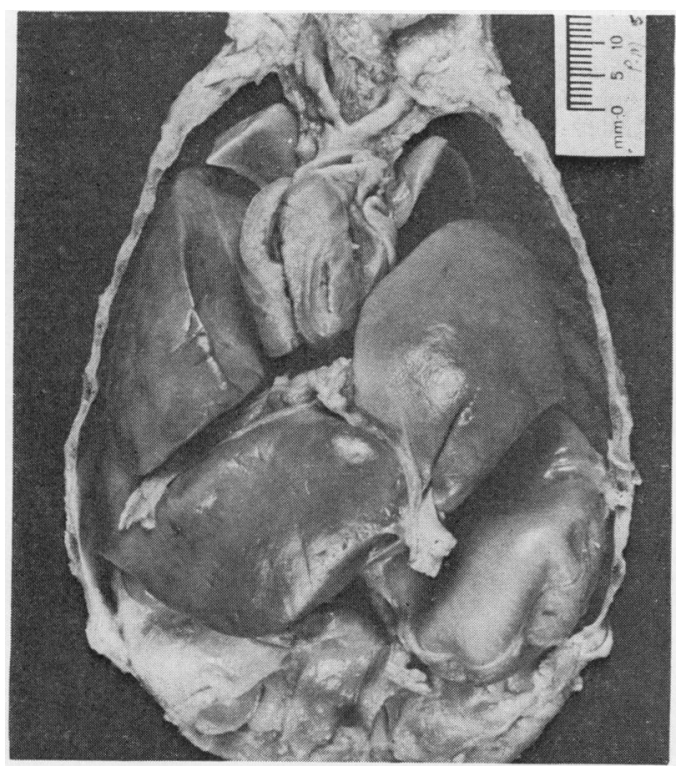

Fig 1 General view of the thoraco-abdominal cavity after the pericardium and thymus have been removed and the heart opened.

Address for reprint requests: Professor JL Emery, Department of Pathology, Children's Hospital, Weston Bank, Sheffield 10. taneous rupture of the membranes occurred. The mother was admitted in premature labour and found to have hydramnios. A normal vertex delivery occurred. The placenta was small and complete.

The baby appeared to be externally normal (weight $1510 \mathrm{gm}$ ) but it was impossible to pass a tube further than one inch down the trachea. She survived for 20 minutes.

Necropsy showed a girl of about 30 weeks' maturity with intense lividity of the head and reck but no jaundice, oedema, or external congenital malformation. Opening the body cavity showed a single pleuroperitoneal cavity with absence of both lobes of the diaphragm (fig 1). Both lungs were reduced to minute, flattened structures measuring $1.5 \mathrm{~cm}$ in greatest diameter and found high up in the thorax. Their lobulation was normal.

The heart was in the midline within a complete pericardial sac. It showed an atrial septum secundum defect, $1.5 \mathrm{~cm}$ in greatest diameter and a persistent left superior vena cava (Duct of Couvier). All other organs, including the whole renal tract, were grossly normal for the age of the child.

The oesophagus travelled down the length of the thorax in its normal position and then approached the stomach through a muscular ring (fig 2). The tissues of the ring were seen, on microscopy, to be the muscular crura of the diaphragm. There were, however, no lateral attachments of the muscle and no remnants of any membranes attached to the chest or abdominal wall. No phrenic nerves could be identified on the outside of the complete pericardial cavity. The placenta showed no abnormality.

Histology revealed a brain of about 30 weeks' maturity and the same applied to all of the other organs examined. Quantitative assessment of the lung based on the right middle lobe showed the numbers of cartilage-bearing bronchi, bronchioles, and alveoli to be within the range of what are considered to be normal for the age. ${ }^{5}$ Serial blocks were taken throughout the larynx, trachea, and lungs, revealing no basic structural abnormality. The pituitary showed congestion only.

\section{Discussion}

This child showed a complete bilateral absence of the diaphragm apart from the presence of the muscular crura. We have been unable to find a report of a 


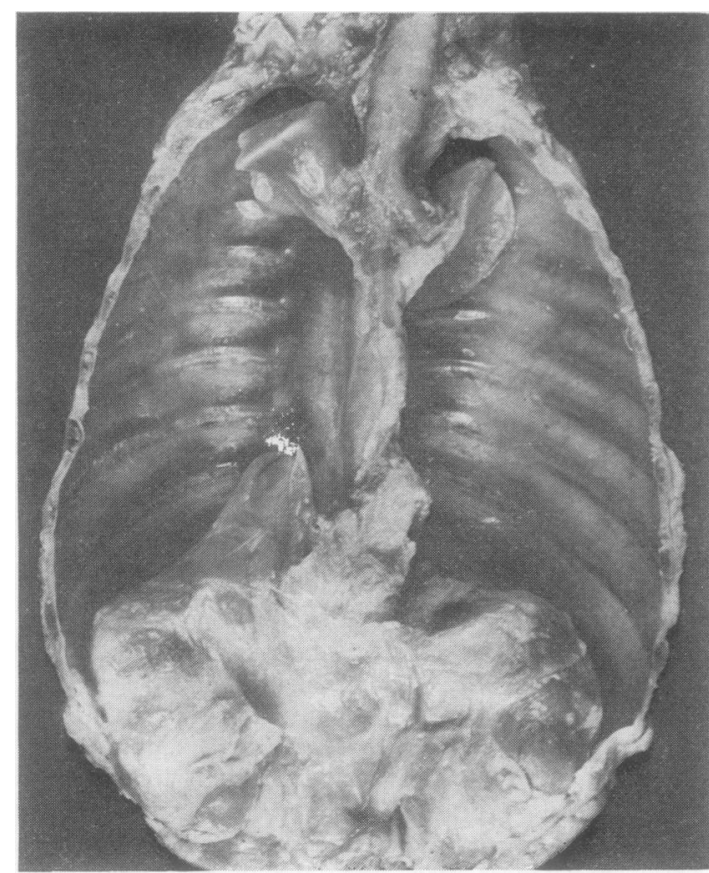

Fig 2 Body cavity after removal of the liver, spleen, and intestine, showing the muscular mass present at the lower end of the oesophagus and normal site of the cardia.

similar case. The only other reported case of bilateral agenesis had $5 \mathrm{~mm}$ wide rudiments on the thoracic wall."

It would seem likely that the deformity arose before the eighth embryonic week, by which time the pleural and peritoneal cavities are separated. The septum secundum develops in the sixth to seventh week while the first diaphragmatic anlage begins in the third week, ${ }^{7}$ which places the likely onset of the deformity in the child between the third and sixth weeks. In this case, those parts of the diaphragm developed from the cervical and dorsal dermatomes were absent but the part derived from the lumbar dermatomes was present.

Cases such as this are not amenable to treatment. There are two developmental points of interest. There was hydramnios associated with an anatomically normal renal and respiratory tract. The lungs were only hypoplastic in appearance, being apparently normal in structure, but unexpanded. This underlines the importance of the diaphragm in the maintenance of the volume of the lungs and of the amniotic fluid.

A second point is that the oesophagus elongated normally, with a normal position of the cardia, in the complete absence of the lateral diaphragm.

\section{References}

1 Ruscic A. Handbook of congenital malformations. Philadelphia: WB Saunders, 1969.

2 Butler N, Claireaux AE. Congenital diaphragmatic hernia as a cause of perinatal mortality. Lancet 1966; 1:619.

3 Gross E. The surgery of infancy and childhood. Philadelphia: WB Saunders, 1953.

4 Baffles TG. Diaphragmatic hernia. In: Mustard WI, Ravitch MM, Snyder WH, Welch KJ, Benson CD, eds. Pediatric surgery. Second edition. Chicago: Year Book Medical Publishers, 1969: 342-56.

5 Sinclair-Smith CC, Emery JL, Gadsdon D, Dinsdale F, Baddeley J. Cartilage in children's lungs: a quantitative assessment using the right middle lobe. Thorax 1976; 31:40-3.

6 Muller WD, Wendler H, Becker H. Beidseitige Aplasia der Zwerchfelles mit Hypoplastic beider Lungen. Klin Paediatr 1978; 190:129-32.

7 Hamilton WJ. Human embryology. Fourth edition. Cambridge: W Heffer, 1972:559. 인 